\title{
Hypercapnia in Hemodialysis (HD)
}

\author{
David Tovbin* \\ Department of Nephrology, Emek Medical Center, Israel
}

*Corresponding author: David Tovbin, Department of Nephrology, Emek Medical Center, Afula, Israel.

Received Date: February 04, 2019

Published Date: February 14, 2019

\section{Introduction}

Acute intra-dialytic exacerbation of hypercapnia in hemodialysis (HD) patient has been initially reported 18 years ago [1]. Subsequent similar case was reported few years later [2]. Common features of both patients were morbid obesity, a previously stable HD sessions and an acute respiratory infection at time of hypercapnia [1,2]. HD patients with decreased ventilation reserve, due to morbid obesity with or without obstructive sleep apnea (OSA) and/or obesity hypoventilation syndrome (OHS) as well as chronic obstructive pulmonary disease (COPD), are at increased risk. COPD is common among HD patients but frequently under-diagnosed [3]. Most COPD patients do well during HD with only mild- moderate pCO2 increases and slightly decreased $\mathrm{pH}$ as compared to non-COPD chronic HD patients [2,4]. However, acute pulmonary congestion or infection or gradual but significant deterioration in respiratory state, may induce hypercapnia with intradialytic exacerbation, hypercapnic encephalopathy and respiratory arrest [1,2,5]. A proposed mechanism is that tissue hypoxia due to hypoxemia and/ or low tissue perfusion as in sepsis and/or shock increase intradialytic acid generation, bicarbonate buffering and production of $\mathrm{CO}_{2}$, which cannot be exhaled at those states [1,2]. Some patients with severe COPD or OHS have baseline chronic severe hypercapnia and need the special measures which will be described below when starting hemodialysis. Symptoms of hypercapnic encephalopathy are correlated stronger with the changes in cerebrospinal $\mathrm{pH}$ induced by rapid diffusion of $\mathrm{CO}_{2}$, than with those of arterial $\mathrm{pH}$ and/or $\mathrm{PCO}_{2}$. Both hypoxemia and on the other hand uncontrolled oxygen therapy with high inspiratory oxygen fractions $\left(\mathrm{FiO}_{2}\right)$, which further decrease respiratory drive, have deleterious effects [5]. Nowadays, morbid obesity and associated obstructive sleep apnea (OSA) and possibly obesity hypoventilation syndrome (OHS) are common in the general population and even more in the population at risk for reaching HD [6-8]. Non-invasive positive pressure ventilation (NIPPV) such as continuous positive airway pressure (CPAP) and bi-level positive airway pressure (BiPAP) are nowadays commonly used in hypercapnic patients $[5,9,10]$. In the
2 case reports and in our experience with similar patients, BiPAP prevented intra-dialytic exacerbation of hypercapnia and possibly respiratory arrest [1,2]. In recent years, new interest was raised to HD dialysate bicarbonate concentration. After standardizing to inflammation malnutrition complex and comorbidities midweek pre-dialysis serum bicarbonate level was recommended as $>22$ $\mathrm{mEq} / \mathrm{L}[11]$. As higher dialysate bicarbonate concentration became more prevalent, a large observation cohort study demonstrated that high dialysate bicarbonate concentration was associated with worse outcome especially in the more acidotic patients [12]. However, still not enough attention is paid to HD dialysate bicarbonate in the increasing number of patients with impaired ventilation, and to their risk of intra-dialytic exacerbation of hypercapnia, hypercapnic encephalopathy and respiratory arrest, especially during pulmonary infection and/or congestion. Thus, avoidance of complications while still correcting metabolic acidosis is a major challenge in these patients. In addition to NIPPV, the second preventive and therapeutic measures of this complication is to reduce dialysate bicarbonate concentration even more than the lower concentrations traditionally used of $33-34 \mathrm{mEq} / \mathrm{L}$ $[1,2]$. Thus, acidosis correction in these situations is dependent on intensive oral sodium bicarbonate between HD sessions [1], similarly to patients without ventilation impairment [13], but with higher doses. In summary, in the increasing number of HD patients with severe acute and/or chronic hypercapnia, lower dialysate bicarbonate concentration to decrease $\mathrm{CO}_{2}$ production, BiPAP during HD to increase $\mathrm{CO}_{2}$ removal, and high dose sodium bicarbonate administration between HD sessions, are probably required to modulate intradialytic exacerbation of hypercapnia as well as metabolic acidosis.

\section{Acknowledgement}

None.

\section{Conflict of Interest}

No Conflict of interest. 


\section{References}

1. Tovbin D, Heimer D, Mashal A, DegtyarP, Avnon LS, et al. (2001) Intradialytic hypercapnic respiratory failure managed by noninvasive assisted ventilation. Am J Nephrol 21(5|): 383-385.

2. Carlos R, Palacios F, Altayeh A, Qian Q (2011) Acute hypercapnic respiratory failure associated with hemodialysis. Dialysis \& Transplantation 40(2): 83-85.

3. Plesner LL, Warming PE, Nielsen TL, Dalsgaard M, Schou M, et al. (2016) Chronic obstructive pulmonary disease in patients with end-stage kidney disease on hemodialysis. Hemodial Int 20(1): 68-77.

4. Alfakir M, Moammar MQ, Ali MI, Alhatem E, Curran RD, et al. (2011) Pulmonary gas exchange during hemodialysis: a comparison of subjects with and without COPD on bicarbonate hemodialysis. Ann Clin Lab Sci 41(4): 315-320.

5. Scala R (2011) Hypercapnic encephalopathy syndrome: A new frontier for non- invasive ventilation? Respir Med 105(8): 1109-1117.

6. Hsu CY, McCulloch CE, Iribarren C, Darbinian J, Go AS, et al. (2006) Body mass index and risk for end-stage renal disease. Ann Intern Med 144(1): 21-28.

7. Schwartz AR, Patil SP, Laffan AM, Polotsky V, Schneider H, et al. (2008) Obesity and obstructive sleep apnea: pathogenic mechanisms and therapeutic approaches. Proc Am Thorac Soc 5(2): 185-192.
8. Berger KI, Goldring RM, Rapoport DM (2009) Obesity Hypoventilation Syndrome. Semin Respir Crit Care Med 30(3): 253-261.

9. Marin JM, Carrizo SJ, Vicente E, Agusti AG (2005) Long-term cardiovascular outcomes in men with obstructive sleep apnea- hypopnea with or without treatment with continuous positive airway pressure: an observational study. Lancet 365(9464): 1046-1053.

10. Shebl RE, Abderaboh MM (2015) Bi-level positive airway pressure ventilation for patients with stable hypercapnic chronic obstructive pulmonary disease. Egyptian Journal of Chest Diseases and Tuberculosis 64(2): 395-398

11. Wu DY, Shinaberger CS, Regidor DL, McAllister CJ, Kopple JD, et al. (2006) Association between serum bicarbonate and death in hemodialysis patients: is it better to be acidotic or alkalotic? Clin J Am Soc Nephrol 1(1): 70-78.

12. Tentori F, Karaboyas A, Robinson BM, Morgenstern H, Zhang J, et al. (2013) Association of dialysate bicarbonate concentration with mortality in the Dialysis Outcomes and Practice Patterns Study (DOPPS). Am J Kidney Dis 62(4): 738-746.

13. Movilli E, Gaggia P, Camerini C, Brunori G, Vizzardi V, et al. (2005) Effect of Oral Sodium Bicarbonate Supplementation on Interdialytic Weight Gain, Plasma Sodium Concentrations and Predialysis Blood Pressure in Hemodialysis Patients. Blood Purif 23(5):379-383. 